Received: 13/07/2019

Revision: 29/11/2019

Accepted: 05/12/2019

OnlineFirst:29/01/2020

\title{
Students' Evaluation on Teaching in Vocational and Technical Schools
}

\section{Edy Supriyadi}

Dr., Faculty of Engineering, State University of Yogyakarta, Indonesia, edy_supriyadi@uny.ac.id

\section{Yuwono Indro $\mathbf{H}$.}

Faculty of Engineering, State University of Yogyakarta, Indonesia, yuwono_indro76@uny.ac.id

\section{Eko Priyanto}

Faculty of Engineering, State University of Yogyakarta, Indonesia, eko_prianto@uny.ac.id

\section{Faranita Surwi}

Faculty of Engineering, State University of Yogyakarta, Indonesia, faranita@uny.ac.id

This study developed an Electronic Evaluation System (E-ES) for students teaching evaluation in Vocational and Technical Schools (VTS). The E-ES model consisted of an application program and an instrument of students' teaching evaluation. This study employed the Analyse Design Develop Implement and Evaluate (ADDIE) model. The implementation of the E-ES model was carried out in 12 VTSs, with the sample of 312 students and 32 teachers selected randomly. The data were collected through questionnaires and interviews and analyzed by using descriptive statistics and t-test. The data collection was conducted twice, at the end of the sixth week and the twelfth week of the odd semester. The results of the study showed that (1) the E-ES application program was successfully developed and was considered feasible at a moderately high degree and; (2) the teaching evaluation instrument was valid (V-Aiken Coefficient Index=0.78), and its reliability with Alfa Cronbach was $\alpha=0.74$; (3) the usability of the model was in a moderately high degree; (4) the students' satisfaction with E-ES was classified into the a moderately high degree, and the teachers' satisfaction of the E-ES was in a moderately high; (5) There was an increase of the teaching quality after the E-ES implementation .

Keywords: E-ES, teaching evaluation, vocational, technical school, teaching

Citation: Supriyadi, E., Indro, Y. H., Priyanto, E., \& Surwi, F. (2020). Students' Evaluation on Teaching in Vocational and Technical Schools. International Journal of Instruction, 13(2), 621-636. https://doi.org/10.29333/iji.2020.13242a 


\section{INTRODUCTION}

Vocational and Technical School (VTS) is an education that strongly emphasizes on practical experience. The learning activities in VTS are mostly conducted in training companies such as large industrial enterprises, workshops, kitchens or shops. Vocational education can provide direct access to employment or be a step on the way to higher education (Danish Ministry of Education, 2014). Despite having the opportunity to continue to higher education, graduates of the vocational education in Indonesia are specifically intended to enter workplaces immediately. The graduates must have a set of competencies to meet the needs and demands of the labor market. To achieve these expected results, all components of vocational education, consisting of the curriculum, teaching staff, facilities, management, and teaching and learning process must meet specified standards.

The role of a teacher is very important in the teaching and learning process. The teacher is very influential on the attitudes and behavior of students, as well as their academic achievement (Blazar, 2016). Moreover, a teacher is expected to make a maximum contribution to the achievement of the school's goals. Every teacher is expected to have optimal performance, especially in teaching. This performance is related to all activities performed by the teachers in educating, directing and guiding the students. Human resources in education, especially teachers need more attention from the government. The increasing number of vocational students in Indonesia that is estimated at 850 thousand students until 2020 must be followed by increasing the number of the teachers and improving the teachers' competencies (Ministry of Education and Culture, 2017). Improving teachers' competency is useful for effective teaching and learning processes. The increasing number of vocational teachers is not balanced with the improvement of teachers' quality. Only $22 \%$ of vocational teachers are qualified teachers with certificates of competency in accordance with the skills being taught. The number of teachers who have the competence to teach is limited. Vocational school students did not adequately receive the teaching and learning process in accordance with the competency program (Ministry of Education and Culture, 2017).

The teaching and learning process needs to be evaluated. The evaluation of teaching is very important to guarantee the quality of the teaching process (Lon, 2016). Effective teachers must master the curriculum and the strategies to achieve learning goals, understand students' characteristics, be able to communicate and interact with students, master learning media, be able to monitor the progress of students'learning, and be responsible for students' learning outcomes (James et al., 2016). Teachers' motivation is one of the main factors that influence students' learning motivation, and determine the effectiveness of learning (Jiying \& Hongbiao, 2016).

The evaluation of teaching by VTS students in Indonesia is not optimal. Some VTSs unsystematically conduct teaching evaluations in the form of questionnaires (paper) which are filled manually by the students. The content of the questionnaire also not only focuses on teaching effectiveness but also on teachers' effectiveness eventhough the concept of teaching effectiveness is significantly different from the concept of teachers' effectiveness (Goran \& Katarina, 2012). Moreover, almost every VTS in Indonesia has 
used Information and Communication Technology (ICT) to support the learning process. Vocational students commonly use ICT, including the internet and mobile phones. Therefore, an online student's evaluation of teaching through ElectronicEvaluation System (E-ES) for VTS is crucial to be developed. E-ES is an electronic or computer-based information system for teaching evaluation.

Schools should conduct students' evaluation of teaching as the students are the source of information and have a perspective on the behavior of their teachers. The students become the elements who have a high intensity in interaction with the teachers. In more frequent contacts with the teacher, the students observe performance-related behaviors and are often not seen by the principal. The essential point in implementing evaluation by students is the purpose and the use of the evaluation results. Teachers, students, and related parties should receive an explanation of the purpose of the evaluation, especially in terms of efforts to improve the quality of teaching and learning process. Awards or incentives for teachers related to the purpose of evaluation also need to be conveyed to the teachers (Cecilia et al., 2014).

The quality of the information system influences the satisfaction of the users. If the user of the information system believes that the quality of the system and information produced from the system are moderately high degree, they will feel satisfied in using the system. Users' satisfaction with an ICT system is the extent to which ICT meets the users' expectations. The users will feel satisfied if the information system can meet their needs. They will be disappointed if the ICT does not match their needs. Satisfaction contributes significantly to the desire to continue the use of ICT (Abdulhakim et al., 2016). The users' satisfaction is a key factor in the success of the information system.

User satisfaction is a personal judgment. The users' satisfaction is a measure of a person's behavior after using certain softwares or application programs (Priyanka et al., 2015). E-ES can be seen as a web-based solution that mediates users (especially students and teachers) and school institutions. The objectives of this study were to develop E-ES model in accordance with user needs, determine the extent of user satisfaction, and usability of the E-ES. The E-ES consisted of an application program and an instrument of students' evaluation of teaching.

\section{CONTEXT AND REVIEW OF LITERATURE}

Vocational education has a very important role in the social and economic development. It will contribute positively to the social and economic development if the curriculum is designed based on the identification and analysis of labor market needs (Mouzakitis, 2010). The curriculum is used as the base of developing teaching tools that include a lesson plan, materials, media, facilities, teaching strategies, and assessment. A highquality lesson plan will assist teachers to maintain learning activities and to achieve learning outcomes optimally. The teachers who develop and implement a lesson plan achieve better effectiveness than those who do not (Beatrice et al., 2015). Likewise, the use of learning strategies generates a positive impact on students' learning outcomes (Westbrook et al., 2013). 
The quality of the teaching and learning process strongly influences students' learning outcomes. Effective teaching and learning process can improve the achievement of students' competencies to support the students' success in the future (Coe et al., 2014). Learning must be related to certain real tasks or real works in the workplace (McCrone et al., 2015). The learning process in vocational schools must be held interactively, pleasantly, and motivate the students to actively participate in accordance with their talents, interests and physical and psychological development. Teaching style and practices such as being approachable, prepared, and genuinely caring about their students' learning can lead to greater students' interest and efforts and ultimately to students' success (Mohd et al., 2019).

The success of a teacher can be obtained if the existing criteria have been achieved. It means that the work has been considered to have a moderately high degree quality. Evaluation of teachers' performance also aims to find out precisely about teachers' activities in the classroom (classroom management), and help them to improve their knowledge and skills which are expected to contribute directly to improve the quality of teaching. There are four sources of evidence of the quality of teaching, i.e. the source of students (students' input), peer assessment (peer review), students' learning achievement, and self-assessment. The results of teaching evaluation will be better and more reliable if the evaluation is conducted by all sources of evidence (Denise \& Lynne, 2016). If one truly wants to understand how well someone teaches, to know what is going on in the classroom, and to determine the quality of instructors' materials, observation is necessary (Henry, 2017).

The use of ICT in education, including in teachers' performance evaluation, is highly recommended to be developed in schools. This is also in line with the results of the International Conference on ICT and Post-2015 Education Conference, the Qingdao Declaration: (1) lifelong learning; (2) online learning innovations; (3) quality assurance and recognition of online learning; and (4) monitoring and evaluation (UNESCO, 2015). E-ES is an electronic or computer-based information system for teaching evaluation carried out by students. E-ES uses a system or a mechanism that utilizes ICT. The E-ES system can be accessed using the internet (local computer network) depending on users' choices and needs. With web-based technology, it allows E-ES to be accessed by users or respondents from anywhere and anytime. Web surveys make it possible to reach worldwide, national, or school intranet networks. The survey is converted into a webpage and placed online. Surveys through the web offer an interface that is familiar and easy to understand by school residents and stakeholders. This method works best when anonymity is needed (Training Technology, 2017). Besides, the results of the study indicated that the evaluation response between the paper-based methods in the classroom and the web-based evaluation process did not differ significantly in most survey items (Stephen, 2002).

\section{METHOD}

This study aimed at developing an E-ES model of students' teaching evaluation. It consisted of an application program, and instrument of students' evaluation on teaching. This development research used an Analyze, Design, Develop, Implement, and Evaluate 
(ADDIE) model. It was carried out through the following stages: (1) Analysis of problems, (2) Design of model development, (3) Development of the model, (4) Implementation, and (5) Evaluation. Selection of this ADDIE model was based on the consideration that the model is coherent, comprehensive, and systematic in accordance with the stages of the development and implementation of E-ES in VTS. This research used mixed (quantitative and qualitative) methods.

The analysis of problems and needs was carried out through interviews, questionnaires and document analysis. The sources of information were students, teachers, principals, and supervisors. Designing the model was conducted by preparing reference books and regulations related to the evaluation of teaching, designing E-ES model, determining experts and practitioners involved in the validation process, and determining schools for implementation. The development of the model was carried out based on the model design of E-ES. Validation of the E-ES model was conducted by experts and practitioners, consisting of two principals, two teachers, two VTS supervisors, one education evaluation expert, two vocational education experts, and two information and communication technology experts. These experts and practitioners were selected from the fields related to the evaluation of teaching using E-ES at VTS. From experts and practitioners, various inputs from several aspects related to E-ES, i.e. aspects of teaching in VTS, evaluation of teaching, ICT, development, and utilization of E-ES were obtained. The criteria as a reference to determine the feasibility of the E-ES System are presented in Table 1.

Table 1

Criteria for Feasibility of the E-ES

\begin{tabular}{ll}
\hline Score & Degree \\
\hline $\mathrm{X}>3.4$ & High \\
$2.8<\mathrm{X} \leq 3.4$ & Moderately High \\
$2.2<\mathrm{X} \leq 2.8$ & Adequate \\
$1.6<\mathrm{X} \leq 2.2$ & Moderately Low \\
$\mathrm{X} \leq 1.6$ & Low \\
\hline
\end{tabular}

The questionnaires of teaching evaluation were validated by five experts. The content validity of the instrument was determined by the V-Aiken coefficient index. The implementation of the E-ES model was carried out in VTSs in the Province of Yogyakarta Special Region, Indonesia. The population of VTS to implement E-ES was 36 VTSs majoring in Electricity in Yogyakarta Special Region Province. The selection of 12 VTS as samples was done purposively, namely VTSs which already had computer and Wifi network facilities to implement E-ES. A total of 312 students and 32 teachers were randomly taken as samples in the implementation of E-ES.

The E-ES was installed on the schools' website on the sixth week of the odd Semester 2017. The students, teachers and principals were given an explanation of the E-ES contents, procedures for filling in the form of teaching evaluation, and how the teachers and principals saw the results of evaluation by students. The points of teaching evaluation were explained in details so that students understood each of the teaching 
evaluation items. This is to avoid or minimize the possibility of students' bias in giving responses.

Teaching evaluation through E-ES was conducted twice. First, it was conducted at the end of the sixth week of the Odd Semester of 2017, immediately after E-ES was posted on the school's web. The students were asked to fill in the form of teaching evaluation on certain subjects through the E-ES. The students evaluated teaching based on their experiences when participating in the teaching and learning for the past six weeks before E-ES was installed. Secondly, it was conducted in the 12th week. the students evaluated the teaching based on the students' experiences when participating in learning for the past six weeks.

The usability of the E-ES was determined after implementation. The usability of the EES model was comprehensive, relevant, and feasible. Comprehensiveness was the completeness of the contents, the complexity of the composition, and the suitability of the implementation procedures. Relevance was the suitability of the E-ES contents with regulation, and the suitability of E-ES system with user needs. Feasibility assessed whether the E-ES system was practical, easy to understand, and simple to implement. The criteria for the usability of the model are presented in Table 2 .

Table 2

Criteria for the Usability of the E-ES

\begin{tabular}{lll}
\hline Score & Category & Conclusion \\
\hline $\mathrm{X}>3.4$ & High & It can be used and be the model \\
$2.8<\mathrm{X} \leq 3.4$ & Moderately High & It can be used \\
$2.2<\mathrm{X} \leq 2.8$ & Adequate & It can be used with minor revisions \\
$1.6<\mathrm{X} \leq 2.2$ & Moderately Low & It can be used with major revisions \\
$\mathrm{X} \leq 1.6$ & Low & It cannot be used \\
\hline
\end{tabular}

\section{FINDINGS}

\section{Electronics-Evaluation System (E-ES)}

The E-ES is a computer-based system of students' evaluation of teaching. The E-ES must meet comprehensive, relevant and feasible criteria. The E-ES could motivate the students to actively participate in conducting teaching evaluation and encourage teachers to conduct better teaching so that students can achieve the expected learning outcomes optimally. Regarding the content and function, E-ES consists of two main aspects, namely the E-ES application program, and the instrument of students' evaluation of teaching.

\section{The E-ES application program}

The developed E-ES Program model consisted of 7 components, i.e. Opening display, Main menu and Sub-menu related to the E-ES function, Goal sub-menu and E-ES usage instructions, Sub-menu of filling in teaching evaluation by students, Sub-menu of evaluation results that can be accessed by the teachers, Sub-menu of evaluation results that can be accessed by principals, and Closing display. 
The E-ES application program was successfully developed using the Google Form. The schools can easily modify or enhance the E-ES program because Google Form is simple and open source. The E-ES program was uploaded into the school's website. Each student was given the E-ES system address. Each student could fill the evaluation of teaching through the E-ES program from the students' mobile phones. Filling in teaching evaluations could be done anywhere by the students, without having to use a computer at school. The teacher could also access the results of evaluation using their mobile phones. The evaluation of teaching through E-ES allows the teacher to find out the strengths and weaknesses of their own teaching. An example of the E-ES display is presented in Figure 1.
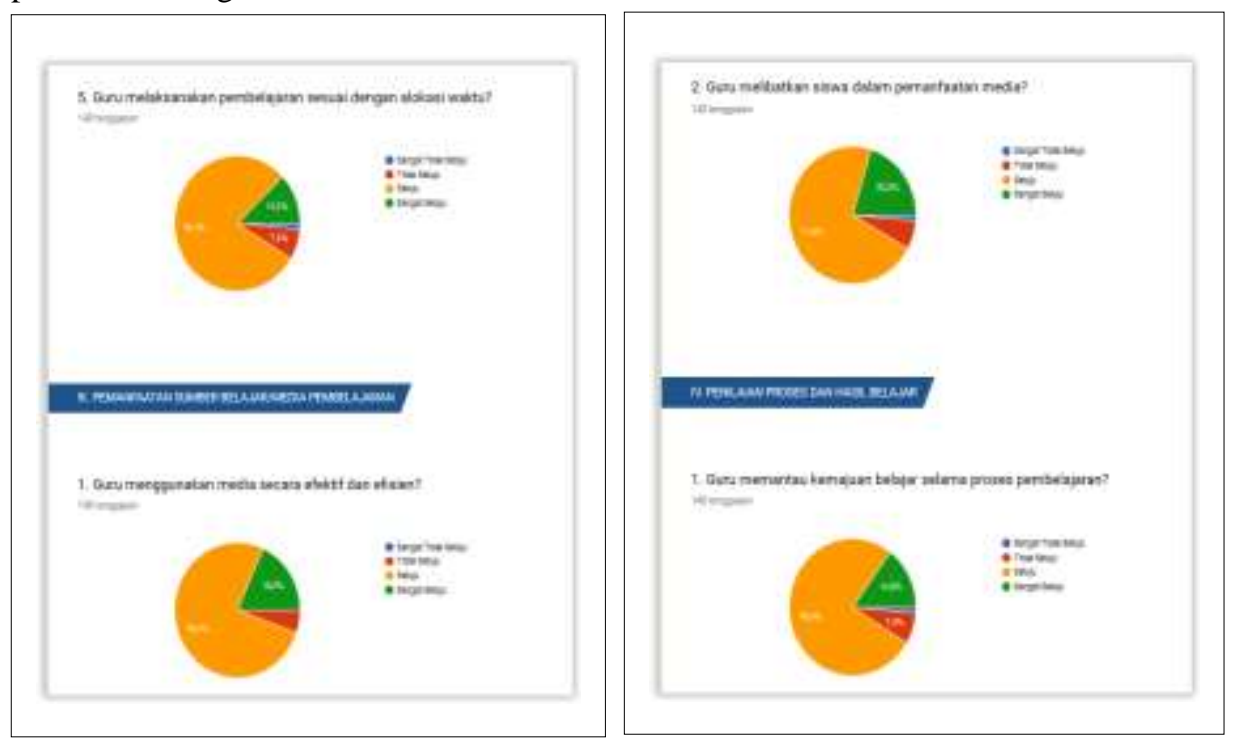

Figure 1

Examples of E-ES Display: Recapitulation of Evaluation Results Per Item

The E-ES program was then validated by five experts, that consisted of a learning expert, an education evaluation expert, and three information and communication technology experts. The expert determination was carried out in accordance with aspects of the E-ES program to be assessed, namely Information and Communication Technology, Learning, and Learning Evaluation. The calculation results showed that the Mean of the E-ES program ranged from 3.07 to 3.20, with the overall Mean=3.11 as presented in Table 3. The feasibility of the E-ES program was considered feasible at a moderately high degree. 
Table 3

The Feasibility of the E-ES

\begin{tabular}{lcl}
\hline \multicolumn{1}{c}{ Components } & Mean & SD \\
\hline Opening display & 3.13 & 0.71 \\
The main menu and sub-menu items related to the E-ES function & 3.08 & 0.70 \\
The goal sub-menu and E-ES usage instructions & 3.13 & 0.74 \\
The sub-menu of filling in teaching evaluation by students & 3.07 & 0.81 \\
The sub-menu of assessment results that can be accessed by teachers & 3.12 & 0.82 \\
The sub-menu of assessment results that can be accessed by & 3.20 & 0.77 \\
leaders/principals & & \\
Closing display & 3.10 & 0.80 \\
Overall & 3.11 & 0.76 \\
\hline
\end{tabular}

\section{Instrument of students' evaluation on teaching}

The development of students' evaluation of teaching referred to the standards of teaching and learning process (Ministry of Education and Culture, 2016), instruments that have been used by the Ministry of Education and Culture to assess teaching, and relevant references. The instruments that have been developed consisted of five main components, i.e. (1) Introduction, (2) Learning Processes, (3) Interactions, (4) Assessment, and (5) Achievement. Introduction consisted of explanation of objectives, scope, mechanism of learning and assessment. The learning process comprised of the accuracy of teaching methods, media, ICT usage, clarity, coherence, and meaningfulness of the materials, and effectiveness of time usage. Interactions in the classroom comprised of motivating and directing students to learn and think critically, interactions among students, and between students and teachers. The assessment comprised of conducting assessments that support learning (assessment for, as, and of learning). The achievement consisted of students' learning achievements in cognitive, skill, and affective domains.

The instrument was validated by five experts, i.e. one expert in vocational education, one learning expert, two education evaluation experts, and one education management expert. The content validity of the instrument was analyzed by calculating the Aiken $\mathrm{V}$ coefficient index. Based on the calculation result, it was obtained the Aiken validity coefficient index for the instrument ranged from 0.74 to 0.88 , with an average of 0.78 as presented in Table 4. The reliability estimation of the instrument was obtained by calculating the reliability of $\alpha$ Cronbach from the data of implementation at schools. Based on the data analysis, it was obtained the value of $\alpha=0.74$.

Table 4

Content Validity of the Teaching Evaluation Instrument

\begin{tabular}{ll}
\hline Components & Average of V Aiken Coefficient Index \\
Introduction & 0.78 \\
Learning Process & 0.88 \\
Interaction & 0.74 \\
Assessment & 0.75 \\
Achievement & 0.78 \\
Overall & 0.78 \\
\hline
\end{tabular}




\section{Usability of E-ES}

The E-ES implementation was conducted in 12 VTSs in the Yogyakarta Special Region Province for four months. The subjects of the implementation were students, teachers, and school principals. The researcher assisted the school in installing the E-ES system and provided an explanation of E-ES to the teachers, and school principals. The teachers and principals then explained to the students and asked them to conduct the teaching evaluation in the determined subjects.

The students' evaluation of teaching through E-ES was conducted twice. First, it was conducted at the end of the sixth week in the odd semester. The students evaluated teaching based on their experiences when participating in learning for the past six weeks (before E-ES was installed). Secondly, it was conducted in the 12th week. the students evaluated teaching based on their experiences when participating in learning for the past six weeks (after E-ES was installed). The data collection on the usability of the E-ES model by the teachers was conducted once at the end of the semester after the second students' evaluation of teaching.

The usability of the E-ES by teachers was presented in Table 5. In general, the E-ES system could be well implemented in schools smoothly, with a Mean model usability score of 3.07 and $\mathrm{SD}=0.60$.

Table 5

The Usability of the E-ES

\begin{tabular}{lll}
\hline Aspect & Mean & SD \\
\hline The content of the E-ES is complete & 3.05 & 0.51 \\
The composition of the E-ES content is coherent & 3.08 & 0.59 \\
The procedures are complete and coherent & 3.20 & 0.60 \\
The content of the E-ES corresponds to the regulation & 3.08 & 0.57 \\
The E-ES system meets the users' needs & 2.86 & 0.76 \\
The E-ES system meets the purpose and scope of the assessment & 3.11 & 0.57 \\
The E-ES system is practical & 3.09 & 0.66 \\
The E-ES system is easy to understand & 3.05 & 0.64 \\
The procedures are simple & 3.09 & 0.63 \\
The procedure is easy to be applied & 3.14 & 0.60 \\
Overall & 3.07 & 0.60 \\
\hline
\end{tabular}

\section{User' Satisfaction with E-ES}

The data on the students and teachers' satisfaction with E-ES were obtained through a questionnaire at the end of the semester. The questionnaire consisted of five aspects, i.e. Content, Accuracy, Format, Easy of Use, and Time Lines. Overall, the results of data analysis of students' satisfaction with E-ES was in a moderately high degree with Mean $=3.15$, and $\mathrm{SD}=0.33$. When viewed from the aspects, every aspect of satisfaction with E-Movev was also classified as a moderately high degree. This means that the students were satisfied with the E-ES, both in its entirety and in every aspect. The teachers' satisfaction with E-ES was in a moderately high degree with Mean = 3.05, and SD = 0.19 . The teacher was also satisfied with every aspect of E-ES. Therefore, both students and teachers were satisfied with the E-ES system. This can be interpreted that E-ES was 
generally suitable to be applied in VTSs. The results of data analysis of students and teachers' satisfaction on E-ES and their differences are shown in Table 6, and Table 7.

Table 6

Students' and Teachers' Satisfaction with E-ES

\begin{tabular}{|c|c|c|c|c|c|c|}
\hline & Studer & & & Teach & & \multirow[b]{2}{*}{ Category } \\
\hline $\begin{array}{l}\text { Aspects of } \\
\text { Satisfactio }\end{array}$ & Mean & SD & Category & Mean & SD & \\
\hline Content & 3.18 & 0.42 & $\begin{array}{l}\text { Moderately } \\
\text { high degree }\end{array}$ & 2.98 & 0.30 & $\begin{array}{l}\text { Moderately } \\
\text { high degree }\end{array}$ \\
\hline Accuracy & 3.05 & 0.52 & $\begin{array}{l}\text { Moderately } \\
\text { high degree }\end{array}$ & 3.09 & 0.43 & $\begin{array}{l}\text { Moderately } \\
\text { high degree }\end{array}$ \\
\hline $\begin{array}{l}\text { Format/ } \\
\text { Display }\end{array}$ & 3.18 & 0.48 & $\begin{array}{l}\text { Moderately } \\
\text { high degree }\end{array}$ & 2.95 & 0.29 & $\begin{array}{l}\text { Moderately } \\
\text { high degree }\end{array}$ \\
\hline Ease of Use & 3.15 & 0.46 & $\begin{array}{l}\text { Moderately } \\
\text { high degree }\end{array}$ & 3.14 & 0.27 & $\begin{array}{l}\text { Moderately } \\
\text { high degree }\end{array}$ \\
\hline Time Lines & 3.19 & 0.49 & $\begin{array}{l}\text { Moderately } \\
\text { high degree }\end{array}$ & 3.06 & 0.40 & $\begin{array}{l}\text { Moderately } \\
\text { high degree }\end{array}$ \\
\hline Overall & 3.15 & 0.35 & $\begin{array}{l}\text { Moderately } \\
\text { high degree }\end{array}$ & 3.05 & 0.19 & $\begin{array}{l}\text { Moderately } \\
\text { high degree }\end{array}$ \\
\hline
\end{tabular}

Overall, there was no difference in the satisfaction with E-ES between the students and teachers. However, the content and the format aspects differed significantly although both aspects were in a moderately high degree. The mean value of the Content aspect of the students $($ Mean $=3.18)$ was greater than that of the content aspect of the teacher $($ Mean $=2.98)$. This means that the level of students' satisfaction in the content aspect was significantly higher than the level of teachers' satisfaction. Likewise, in the aspect of the form, the level of students' satisfaction $($ Mean $=3.18$ ) was significantly higher than the level of teachers' satisfaction (Mean $=2.95)$.

Table 7

Differences in Students' and Teachers' Satisfaction with The E-ES

\begin{tabular}{lcccl}
\hline Aspects of & Mean & & & \\
Satisfaction & Difference & $\mathrm{t}$ & Sig. & Significance \\
\hline Content & 0.202 & 2.582 & 0.010 & Significant \\
Accuracy & -0.040 & -0.42 & 0.675 & Not Significant \\
Format/Display & 0.227 & 2.59 & 0.010 & Significant \\
Ease of Use & 0.016 & 0.184 & 0.854 & Not Significant \\
Time Lines & 0.128 & 1.409 & 0.160 & Not Significant \\
Overall & 0.108 & 1.705 & 0.090 & Not Significant \\
\hline
\end{tabular}

\section{Teaching Quality Improvement}

The results of teaching evaluation by the students through E-ES are expected to be used as accurate input for the teachers to improve their teaching quality. The teachers could identify which learning components were moderately high degree, and which teaching components needed improvement. The data collection of teaching evaluation by students was conducted twice. The results of data analysis of the first teaching evaluation by students showed that teaching was generally classified as a moderately 
high degree $($ Mean $=3.15 ; \mathrm{SD}=0.50)$. The results of the second teaching evaluation were also in a moderately high degree category (Mean $=3.38 ; \mathrm{SD}=0.34$ ). By comparing the two results of student evaluations, there was a significant increase in the quality of teaching after the implementation of E-ES $(\mathrm{t}=9.59$; sig. 0.00). It is presented in Table 8. The teaching evaluation consists of five components, i.e. introduction, learning process, interaction, assessment, and achievement of learning outcomes. The results of data analysis in each component were classified as a moderately high degree. When viewed from each component of teaching, there was a significant increase in each component of teaching quality between before (first evaluation) and after (second evaluation) the implementation of E-ES.

Tabel 8

Differences in the Results of Teaching Evaluations by the Students before and after EES Implementation

\begin{tabular}{lllll}
\hline Aspects of Evaluation & Mean Difference & $\mathrm{T}$ & Sig. & Significance \\
\hline Introduction & 0.531 & 22.472 & 0.000 & Significant \\
Learning Process & 0.460 & 12.451 & 0.000 & Significant \\
Interaction & 0.367 & 7.961 & 0.000 & Significant \\
Assessment & 0.407 & 8.740 & 0.000 & Significant \\
Achievement & 0.653 & 14.022 & 0.000 & Significant \\
Overall & 0.483 & 13.596 & 0.000 & Significant \\
\hline
\end{tabular}

\section{DISCUSSION}

Based on the results of the implementation of E-ES in VTS, the usability of E-ES was in a moderately high degree $(\mathrm{Mean}=3.07 ; \mathrm{SD}=0.60)$. The content and composition of the E-ES were coherent and met the regulations and schools' needs. Online students' teaching evaluations help students to provide feedback for the teachers. The teachers and principals found out the quality of teaching more easily and faster based on the students' evaluations. The use of information and communication technology (online) makes it easier for all parties to be involved and participate in E-ES. This is in line with the results of the LIP study (2008) showing that online evaluation will be a momentum for schools to relieve the administrative burdens of teachers and staff, as well as future students' workloads. The online evaluation may become widespread at all levels if more and more school administrators realize the value of convenience of technology to help in the course evaluation.

The students' satisfaction with the E-ES implementation shows a moderately high degree. The students understand its purpose and importance, as well as the mechanism for teaching evaluation. Through E-ES, they can evaluate in more detail without fear because the teachers will not know them. They feel confident that the results of their assessment through E-ES will be used as feedback for the teachers so that there will be efforts by the teacher to improve the quality of learning. According to the students, they will continue to actively participate in the teaching evaluation through E-ES. This is in accordance with the study of Khorsandi et al. (2012) about using online for evaluating the quality of learning. The findings show that students prefer online methods to evaluate teaching quality $(\mathrm{p}<0.001)$ than the traditional methods. Compared to the 
traditional evaluation, the online evaluation tends to have greater benefits. The online evaluation of teachers may be suitable for an alternative to the paper evaluation.

The online evaluation can be used without any kind of concern. The findings of the study of Esmael (2017) revealed that many students wrote that they felt they could give richer, more thoughtful, and more useful feedback when they completed the online evaluation on their own, at a time of their preference, with no time constraints. Therefore, the use of online feedback should be considered in the institution in the future.

The teachers must pay attention when the data show that students' perception of teacher performance in teaching is low. This can lead to their negative attitude towards teaching. They must make every effort to show the quality of teaching to generate high students' perceptions. They must provide an adequate, suitable and conducive learning and teaching environment for the students. This will create a positive attitude of students towards teaching. Increasing the students' satisfaction, commitment and interest in learning will influence the improvement of learning achievement (Hassan et al, 2017). Related to the students' satisfaction with E-ES, the beliefs about the importance of using online evaluation of teaching will influence students' participation in the evaluation process (Cathy et al, 2014). The principals should explain the importance of evaluating teaching, and the benefits of feedback from the students to improve the quality of teaching and learning.

The teachers' satisfaction with E-ES was in a moderately high degree. Ilias (2016) concluded that teachers who had a positive attitude or satisfaction with school selfevaluation also had a collaborative culture, and accepted the values of commitment to treating humans as moderately high degree learners. There were no differences in the teachers' attitudes toward the teaching evaluation based on their work experience. However, some senior teachers, whose age was nearing retirement, had difficulty accessing the results of the E-ES. Some teachers did not understand or were not used to using the information and communication technology, including the internet. This is consistent with the results of the Inspectorate (2008) study, which found that many teachers lacked an understanding of ICT, and some other teachers did not use ICT to support learning. Senior teachers tend to be conventional, and are reluctant to learn and use ICT.

The teachers' satisfaction with E-ES could also be seen from his or her employment status. Teachers who were on annual contracts were more likely to improve their instruction than teachers who were on continuing contracts (Sun et al, 2015). It may be that career teachers are perceived to be more stressed to improve under the performance accountability system. The results of the study of Otilia (2014) revealed that the teachers' attitude towards evaluating the quality of teaching depends on several factors, including the age of the teachers, the learning system, and the experience of the teachers in teaching.

The evaluation of teaching is an effort to improve the quality of learning. The purpose of teacher evaluation is to accelerate professional growth and development that leads to 
instructional improvement and greater success for students, not to create anxiety and concerns about job security among educators. The evaluation of teaching can create a growth mindset that instills confidence in instructors. Rather than being demoralized by performance rankings that create a fixed mindset, the teachers can concentrate on their efforts and compare their current progress to past performance. They can then focus on developing better teaching methods and skills, rather than fearing or resenting comparisons to others (The Aspen Institute, 2016). E-ES, if properly administered, can be a useful tool for evaluating a teacher's pedagogical performance.

When conducted correctly, the results of evaluations of teaching by students became a valid and reliable source of information for improving the quality of learning (Le, 2016). Besides, the teacher will be positive about learning assessment by students (Inko-Tariah, 2013). However, there are several other factors associated with improving the quality of learning, namely schools' support in the form of teacher professional development, principal feedback, and peer support (Sun et al, 2015). In conclusion, although the student evaluation of teaching remains controversial, the data from students can be extremely illuminating. The students' evaluation of teaching certainly has value and is worth the effort taken to collect it. Nevertheless, it would be a mistake to assume that the student evaluation provides a complete assessment of all important aspects at the level of teaching (Evrim \& Seda, 2012).

Through E-ES, the principal can access the results of students' teaching evaluation, and use it as a basis in fostering teachers to improve the quality of teaching. The principal has an obligation to supervise the teacher in teaching. The information about the quality of teaching obtained through E-ES is very useful for principals in conducting supervision. Principal supervision of teachers is very important in improving the quality of teaching. This is in accordance with the results of the study of Darishah et al (2017), who concluded that if teaching supervision was carried out properly, the attitude and competencies of teachers in teaching would increase. Teacher evaluation operates as a way of promoting teachers' professional development and empowering them as practitioners rather than a way of making critical decisions regarding their careers (Tarhan et al., 2019).

\section{CONCLUSION AND RECOMMENDATIONS}

Based on the results of the development and discussion of the E-ES model for Vocational and Technical Schools, it can be summarized as follows. Firstly, the developed model of E-ES system was complete and coherent, relevant to regulations and users' needs. The instrument of students' teaching evaluation had a moderately high content validity. Secondly, the E-ES was successfully implemented in Vocational and Technical Schools. The usability of E-ES was in a moderately high degree. Online teaching evaluation assisted the students to provide feedback to the teachers. Thirdly, the students' satisfaction with E-ES implementation was in a moderately high degree. The teachers identify the quality of teaching corresponding to students' perceptions more easily and faster. Fourthly, there was an increase in the quality of teaching after the E-ES implementation. 
Students' evaluation of teaching through E-ES needs to be disseminated in Vocational and Technical Schools. Vocational principals and teachers are expected to learn the EES, and use it as an effort to improve teachers' performance in teaching. The E-ES should be used as a reference for researchers in conducting further studies related to the students' evaluation of teaching.

\section{REFERENCES}

Abdulhakim, E. D., Nurlida, B., \& Norasikin, F. (2016). Impact of system quality on users' satisfaction in continuation of the use of e-learning system. International Journal of e-Education, e-Business, e-Management and e-Learning, 6(1), 13-20.

Beatrice, W. N., Gathu, A., \& Bomett, J. E. (2015). Influence of monitoring and evaluation by principals on effective teaching and learning in public secondary schools in Githunguri district. Journal of Education and Practice, 6(9), 10-17.

Blazar, D. (2016). Teacher and teaching effects on students' academic performance, attitudes, and behaviors (Unpublished doctoral dissertation). Harvard Graduate School of Education.

Cathy, W., \& Kevin, T. (2014). Strategies to increase university students' participation. The Turkish Online Journal of Educational Technology, 13(4), 105-114.

Cecilia, K. Y. C., Lillian, Y. Y. L., \& Min, Z. (2014). Teachers' perceptions of student evaluations of teaching. Educational Research and Evaluation: An International Journal on Theory and Practice, 20(4), 275-289.

Coe, R., Aloisi, C., Higgins, S., \& Major, L. E. (2014). What makes great teaching? Review of the underpinning research. Project Report. London: Sutton Trust.

Danish Ministry of Education. (2014). Improving vocational education and trainingoverview of reform of the Danish vocational education system. Denmark: Author.

Darishah, P., Daud, Y., \& Omar, F.M.S. (2017). Teaching and learning supervision by school management, attitude of teachers and competency of teaching. International Journal of Development and Sustainability, 6(10), 1367 - 1381.

Denise, C., \& Lynne, H. (2016). Evaluation of teaching. HERDSA Review of Higher Education, 3, 25-55.

Esmael, S. (2017). Teaching quality evaluation: Online vs. manually, facts and myths. Journal of Information Technology Education: Innovations in Practice, 16, 277-209. https://doi.org/10.28945/3904 (CC BY-NC 4.0).

Evrim, Ü., \& Seda, C. (2012). Student evaluation of teachers: A case study at tertiary level. Int. Journal on New Trends in Education and Their Implications, 3(4), 92 - 99.

Goran, H., \& Katarina, P. (2012). Differentiating between student evaluation of teacher and teaching effectiveness. J. of Information and Organizational Sci, 36(2), 123 - 134. 
Hassan, B., Maizam, A., Kahirol, M. S., \& Awang, H. (2017). Students' perceptions of their teachers' performance in teaching engineering drawing in Nigerian tertiary institutions. Traektoriâ Nauki = Path of Science, 3(10).

Henry, A. H. (2017). Student evaluations of teaching are an inadequate assessment tool for evaluating faculty performance. Cogent Education, 4(1), $1-8$.

Ilias, M. (2016). Characteristics of teachers with positive attitudes towards school selfevaluation in Greece: A comparison between primary and secondary school teachers (Unpublished master thesis). Department of Education University of Oslo.

Inko-Tarian, D. C. (2013). Attitude of lecturers toward students' evaluation of their teaching effectiveness in Nigerian universities. J. of Edu. and Practice, 4(15), $21-26$.

Inspectorat. (2008). ICT in schools. Dublin: Evaluation Support and Research Unit.

James, K., Pamela, S., \& Linda, B. (2016). Effective teaching. Reprint of 2014 Report. Berkshire England: Education Development Trust.

Jiying, H., \& Hongbiao, Y. (2016). Teacher motivation: Definition, research development and implications for teachers. Cogent Education, 3(1), 1 - 18.

Khorsandi, M., Kobra A., Ghobadzadeh, M., Kalantari, M., Seifei, M. (2012). Online vs. traditional teaching evaluation: A cross-sectional study. Procedia - Social and Behavioral Sciences, 46, 481-483.

Le Hoa Phan. (2015). Student surveys of teaching \& learning quality: An issues paper to contextualize current practices in higher education. Australia: The University of Queensland. Retrieved from https://itali.uq.edu.au/files/235/StudentSurveys_ITaLI_30Apr_2015.pdf.

Lip, P. C. H. (2008). Evaluating teaching and learning from students' perspectives in their classroom through easy-to-use online surveys. International Journal of Cyber Society and Education, 1(1), 33-48.

Lon, L. (2016). Monitoring and evaluating the performance of teachers through the process of observation in the classroom. European J. of Multidisciplinary Studies, 1(2).

McCrone, T., O’Beirne, C., Sims, D., \& Taylor, A. (2015). Review of technical education. Slough: NFER.

Ministry of Education and Culture. (2017). Vocational school revitalization implementation strategy: 10 steps of vocational revitalization. Jakarta: Directorate of Secondary School Management.

Ministry of Education and Culture. (2016). Regulation of minister of education and culture number 22-year 2016 regarding basic and secondary education process standards. Retrieved from http://www.bsnp-indonesia.org/wp-content/uploads /2009/06/Permendikbud_Tahun2016_Nomor022_Lampiran.pdf. 
Mohd, E. I., Suhaizal, H., Norhasyimah, H., Noorazman, A. S., Saiful, H. M., Khairul, A. M. D., Nor, F. M. A., Mohd, A.S., \& Nur, Z. S. K. (2019). Factors that influence students' learning: An observation on vocational college students. Journal of Technical Education and Training 11(1), 093-099.

Mouzakitis, G. (2010). The role of vocational education and training curricula in economic development. Procedia - Social and Behavioral Sciences, 2, 3914-3920.

Otilia, C. (2014). Roles and strategies of teacher evaluation: Teachers' perceptions. Procedia - Social and Behavioral Sciences, 180, 916-923.

Priyanka, T., Durga, K., \& Subramani, A.K. (2015). User satisfaction towards Facebook. ZENITH Int. Journal of Business Economics \& Management Research, 5(6).

Said, A. (2018). Vocational teaching-learning through the eyes of undergraduate vocational students in Malta: a qualitative exploratory study. International Journal for Research in Vocational Education and Training, 5(1), 42-63.

Stephen, W. T. (2002). Online student evaluation of instruction: An investigation of non-response Bias. Paper presented at the 42nd Annual Forum of the Association for Institutional Research Toronto, Canada.

Sun, M., Brock, M., \& Jihyun Kim. (2015). Teachers' use of evaluation for instructional improvement and school supports for this use. In making the most of multiple measures: The impacts and challenges of implementing rigorous teacher evaluation systems. New York: Teachers College Press.

Tarhan, H., Karaman, A., Kemppinen, L., \& Aerila, J. (2019). understanding teacher evaluation in Finland: A professional development framework. Australian Journal of Teacher Education, 44(4).

The Aspen Institute. (2016). Teacher evaluation a roadmap for improvement and support systems. Washington, DC: Author.

Training Technologies. (2007). Education survey services for course evaluation, student assessment, testing capabilities, and more. Retrieved from http://www.surveytracker.com/services/educate.htm.

UNESCO. (2015). Leveraging information and communication technologies to achieve the post-2015 education goal. Report of the International Conference on ICT and Post2015 Education. Qingdao, People's Republic of China.

Westbrook, J., Durrani, N., Brown, R., Orr, D., Pryor, J., Boddy, J., \& Salvi, F. (2013). Pedagogy, curriculum, teaching practices and teacher education in developing countries. Final Report. Education rigorous literature review. London, UK: Department for International Development. 